\title{
Comparative Study of Sex Steroid Levels of Persian Sturgeon, Acipenser persicus Males in Responding Negative and Positive to LHRH-A ${ }_{2}$ Hormone
}

Mohammad Sadegh Aramli*, Mohammad Reza Kalbassi ${ }^{1}$ and Rajab Mohammad Nazari²

${ }^{1}$ Aquaculture Department, Faculty of Marine Sciences, Tarbiat Modares University, Noor, Iran

${ }^{2}$ Rajaei sturgeon Fish Farm, Sari, Iran

\begin{abstract}
Gonadotropin-releasing hormone agonists ( $\mathrm{GnRHa}$ or LHRHa) have been used extensively in order to stimulate the release of pituitary luteinizing hormone $(\mathrm{LH})$ required to induce sexual maturation (e.g., spermiation). In this research, blood serum testosterone $(T), 11$-ketotestosterone $(11-K)$ and progesterone $\left(P_{4}\right)$ levels were measured in Persian sturgeon, Asipenser persicus (Borodin, 1897), males during propagation season. The type and dose of hormone administration for artificial propagation were $\mathrm{LH}-\mathrm{RH}-\mathrm{A}_{2}$ and $5 \mu \mathrm{g} \mathrm{\textrm {kg } ^ { - 1 }}$, respectively. In males which responded by spermiating, serum steroids levels $\left(\mathrm{T}, 11-\mathrm{K}\right.$ and $\mathrm{P}_{4}$ ) were higher than in non spermiating males. Following hormonal stimulation, levels of all three steroids increased significantly in spermiting males $14 \mathrm{~h}$ after $\mathrm{LHRH}-\mathrm{A}_{2}$ injection. T levels increased slightly in non spermiting males and other steroids did not change during the spermiation process. The rise of T levels in both males show that this steroid as a dominant and key androgen related with maturation in Persian sturgeon.
\end{abstract}

Keywords: Testosterone; 11-ketotestosterone; Progesterone; Persian sturgeon

\section{Introduction}

Synthetic hormones using have been increasingly employed in various culture situations during the past two decades, in order to control the reproduction of economically important fish [1]. LHRH is an equivalent of the GnRH, and a small injection of LHRH is commonly used to assess breeding readiness, to test the ability to release temporary LH and sex-steroids, and to test whether the pituitary and/or the gonads are functional. In male broodstocks, they advance the beginning of spermiation, increase the amount of expressible milt and spermatozoa production. On the other hand, some of studies have demonstrated that in about 15 percent of the males have abnormally thin testes and negatively response to hormone injection, finally produced semen with low concentration of germinal cells [2].

Sturgeons are commercially and culturally important in the world. During recent years stocks of this valuable fish were dramatically decreased and almost all sturgeon species were endangered or threatened [3]. Therefore, understanding of sturgeon reproduction provides a key to restocking of theirs populations in nature.

The sex steroids (e.g., androgens and progesterone) are inorganic components which play an essential role in hormonal control of the reproduction in fish including sturgeons [4]. Androgens (T and $11 \mathrm{~K}$ ) are effective in supporting either the whole process of spermatogenesis or at least some steps such as spermatogonia multiplication and spermatocyte formation or maturation. On the other hand, progesterone advance and induce spermiation in fish, increase milt production and stimulate spermatozoa motility [5].

Although various researches on gonadal abnormalities and steroid hormone levels were reported in sturgeon from the Caspian Sea, but less study has been done in male broodstocks of Persian sturgeon. Therefore, in this paper, we investigated changes in the levels of sex steroid hormones of testosterone, 11-ketotestosterone and progesterone in "spermiting" (positive responding) and "non spermiting" (negative responding) males of Persian sturgeon after stimulation by LHRH-A hormone.

\section{Material and Methods}

The experiments were carried out during March- April 2011. Persian sturgeon breeders were captured from the southern Part of the Caspian Sea and transported to the Rajaei sturgeon fish farm, Sari, Iran. Fish (12 male broodstock) were injected by LHRH-A hormone at a dosage of $5 \mu \mathrm{gKg}^{-1}$ of body weight by placing the syringe in the muscles between the dorsal and lateral scutes. Temperature during the experiment was between $12.5^{\circ} \mathrm{C}$ and $14^{\circ} \mathrm{C}$. Four blood samples were taken from each of 12 males during the course of the experiment: (a) at time of injection, (b) 8 , (c) 14 and (d) $24 \mathrm{~h}$ after treatment. Seven males $(119.34 \pm 4.32 \mathrm{~cm}$ total length and $15.73 \pm 0.34=\mathrm{kg}$ weight) were spermiating $14 \mathrm{hr}$ after the treatment and five males $(121.23 \pm 4.47 \mathrm{~cm}$ total length and $14.81 \pm$ $0.57=\mathrm{kg}$ weight) did not mature during the experiment.

\section{Protocol and preparation of blood samples}

Blood samples were collected from the behind of the anal fin using a $4 \mathrm{ml}$ syringe, held until separation of the serum; then all sera were collected into Eppendroff tubes and stored in liquid nitrogen and transferred to the Laboratory of Marine Sciences Faculty of Tarbiat Modares University, Noor, Iran.

\section{Sex steroids analysis}

Sex steroids concentrations (ng $\mathrm{ml}^{-1}$ ) of testosterone (T), 11-ketotestosterone $(11-\mathrm{K})$ and progesterone (P4) were determined using the enzyme-linked immunosorbent assay (ELISA) according to Semenkova et al. (2002) [6].

*Corresponding author: Mohammad Sadegh Aramli, Aquaculture Department Faculty of Marine Sciences, Tarbiat Modares University, Noor, Iran, Tel: (+98) 9147541626; E-mail: msaramli@gmail.com

Received January 08, 2013; Accepted March 29, 2013; Published April 10, 2013

Citation: Aramli MS, Kalbassi MR, Nazari RM (2013) Comparative Study of Sex Steroid Levels of Persian Sturgeon, Acipenser persicus Males in Responding Negative and Positive to LHRH-A Hormone. J Aquac Res Development 4: 177 doi:10.4172/2155-9546.1000177

Copyright: (c) 2013 Aramli MS, et al. This is an open-access article distributed under the terms of the Creative Commons Attribution License, which permits unrestricted use, distribution, and reproduction in any medium, provided the original author and source are credited. 
Citation: Aramli MS, Kalbassi MR, Nazari RM (2013) Comparative Study of Sex Steroid Levels of Persian Sturgeon, Acipenser persicus Males in Responding Negative and Positive to LHRH-A Hormone. J Aquac Res Development 4: 177 doi:10.4172/2155-9546.1000177

Page 2 of 3

\section{Statistical analysis}

The data were analyzed using one-way analysis of variance (ANOVA), followed by Duncan's multiple range test (DMRT) at $\mathrm{P}<0.05$.

\section{Result}

In this experiment, males spermiated approximately $14 \mathrm{hr}$ after the hormonal stimulation. In males that responded by spermiating, serum steroid levels (testosterone,11-ketotestosterone and progesterone) were higher than in non spermiating males, the difference was significant $(\mathrm{P}<0.05)$ (Figures 1-3). At the beginning of spermition $(14 \mathrm{hr}$ after

\section{Testosterone $(\mathrm{T})$}

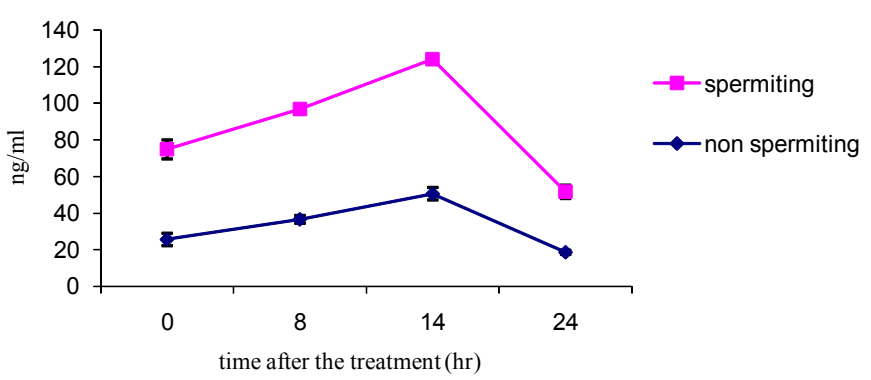

Figure 1: Serum T levels in Persian sturgeon males after the LHRH-A injection. Difference is significant in comparison with the levels in non spermiating males (ANOVA: $d f=7, F=34.71, P<0.05$ ). Data presented as the mean \pm SE.

Progesterone $\left(\mathrm{P}_{4}\right)$



Figure 2: Serum $\mathrm{P}_{4}$ levels in Persian sturgeon males after the LHRH-A injection. Difference is significant in comparison with the levels in non spermiating males (ANOVA: $d f=7, F=26.37, P<0.05$ ). Data presented as the mean \pm SE.

11- Ketotestosterone (11K)

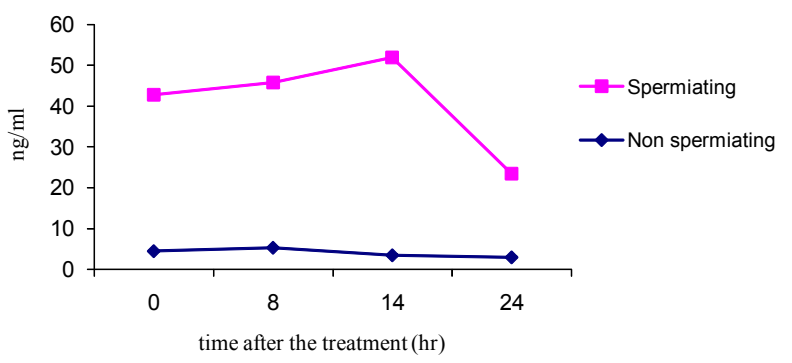

Figure 3: Serum $11 \mathrm{~K}$ levels in Persian sturgeon males after the LHRH-A injection. Difference is significant in comparison with the levels in non spermiating males (ANOVA: $d f=7, F=224.6, P<0.05$ ). Data presented as the mean \pm SE.
LHRH-A injection) $\mathrm{T}, 11 \mathrm{~K}$ and $\mathrm{P}_{4}$ rose in spermiating males and decreased sharply at the end of spermition. In comparison, just the $\mathrm{T}$ levels increased slightly in non spermiting males (Figure 1), whereas $11 \mathrm{~K}$ and $\mathrm{P}_{4}$ concentrations did not change during the spermiation process (Figures 2 and 3 ).

\section{Discussion}

In captivity, GnRH particularly $\mathrm{LH}$ secretion from pituitary, functions are disrupted in all sturgeon species, therefore synthetic or natural reproductive hormones should be applied for inducing final sperm maturation [7]. The luteinizing hormone-releasing hormone (LHRH) is a hypothalamic decapeptide and main positive regulator of luteinizing hormone (LH) secretion from pituitary cells. In fish, LH released from pituitary acts on testis to stimulate progesterone production that regulate sperm maturation in the seminal plasma, by increasing intracellular $\mathrm{pH}$ and cAMP [8-10]. The using of LHRHa hormone in spermiation induction has been reported in some sturgeon species (Persian sturgeon by Nazari et al., 2009 [3]; Chinese sturgeon by Wei et al., 2007 [11]; Russian sturgeon by Barannikova et al., 2006 [12]; Stellate sturgeon by Semenkova et al., 2002 [6]; Siberian sturgeon by Williot et al., 2002 [13]. However, some species may not respond (no spermitaion) to hormone injections. In this regards, investigation of steroid hormone levels between the two groups (spermiation and non spermiation species) can be important.

Gonadal abnormalities has been observed in Caspian sturgeon and is followed by changes in serum steroid levels [4]. The comparison of steroids between mature and immature fish can highlight the main steroids involving in final maturation.

In this study, the levels of $\mathrm{P}_{4}$ and $11 \mathrm{~K}$ did not show significant change in non spermiating males of Persian sturgeon, while $\mathrm{T}$ levels shown the small peak during stimulation period. In the spermiating males, the levels of T, $11 \mathrm{k}$ and $\mathrm{P} 4$ increased after LHRH-A injection and maximum levels this steroids seen at time of spermiation $(14 \mathrm{hr}$ after injection). Our findings, concerning steroid levels in Persian sturgeon males are in agreement with results reported by Semenkova et al. (2002) [6] in Stellate sturgeon, Acipenser stellatus (Pallas) which, levels of $\mathrm{T}, 11 \mathrm{~K}$ and $\mathrm{P} 4$ elevate after LHRH-A injection in spermiating males, whereas such elevations were not observed in non spermiating males. Also our data confirmed by Artyukhin et al. (2006) [2] in Russian sturgeon, Acipenser gueldenstaedti (Brandt) and Barannikova et al (2004) in Sterlet, Acipenser ruthenus L. Possible reasons for the absence spermiation and low levels of steroids after hormonal stimulation were: (1) damage of steroidogenesis process (2) delay of the maturation and (3) not completed stage of the spermatogenesis $[6,14]$. On the other hand, Environmental pollution is one of the major factors which can disrupt the reproduction in fish at all gonadal stages [14].

Testosterone appears to play an important function in several stages of the sexual cycles in sturgeons [4]. According to our results. The higher levels of $11 \mathrm{~K}$ being seen in spermiating males but this levels were lower than the $\mathrm{T}$ level. The high level of $\mathrm{T}$ at the beginning of spermiation show that the $\mathrm{T}$ is probably a main steroid in maturation of Persian sturgeon. similar results were reported on same species where the levels of T and 11-KT increased after LH-RH-A injection [15]. Also, in another study on Great sturgeon, Huso huso L, Russian sturgeon and Stellate sturgeon males revealed that $\mathrm{T}$ and $11 \mathrm{~K}$ levels have a increasing trends during maturation stages [16]. Previous researches shown that $\mathrm{T}$ and $11 \mathrm{~K}$ are predominant androgen in males of teleost species and $\mathrm{T}$ acts a precursor of $11 \mathrm{~K}$ and could be involved in spermatogenesis process $[15,17]$. 
Citation: Aramli MS, Kalbassi MR, Nazari RM (2013) Comparative Study of Sex Steroid Levels of Persian Sturgeon, Acipenser persicus Males in Responding Negative and Positive to LHRH-A Hormone. J Aquac Res Development 4: 177 doi:10.4172/2155-9546.1000177

In regard to P4 levels suggest that it is involved in controlling key stages in the reproduction cycle, though, enough information have not yet obtained for confirmation its role as a key factor in stimulating of sexual maturation of sturgeons [18]. In this experiment, the levels of P4 were low in comparison with androgens levels. Actually, high androgens levels especially $\mathrm{T}$ in both males of Persian sturgeon despite the different states of sex maturation could be indicated the key role of testosterone in reproductive cycle.

In summary of this study, spermiation of Persian sturgeon by LHRH-A2 injection preceded by sharp changes of sex steroid levels in the spermiating males in comparison to non spermaiting males. Also our results indicate that $\mathrm{T}$ and $11 \mathrm{~K}$ may be considered as the dominant androgen in final maturation of Persian sturgeon spermatozoa.

\section{Aknowledgements}

The authors would like to thank Mr. Noori for his substantial assistance during the research work. Thanks also to the staff of Rajaei Sturgeon Fish Farm (Sari, Iran) for their help and support during the implementation of this experiment. This research was supported by Tarbiat Moadres University (TMU), Tehran, Iran.

\section{References}

1. Constantinos C. Mylonas, Yonathan Zohar (2001) Use of GnRHa-delivery systems for the control of reproduction in fish. Reviews in Fish Biology and Fisheries 10: 463-491.

2. Artyukhin EN, Semenkova TB, Bayunova LV, Lunev GE, Barannikova IA (2006) Histological assessment of the testes coupled with determinations of sex steroid levels in Acipenser gueldenstaedtii males responding negatively to pituitary treatment. J Appl Ichthyol 22: 361-363.

3. Nazari RM, Modanloo M, Ghomi MR, Ovissipor MR, (2010) Application of synthetic hormone LHRH A2 on the artificial propagation of Persian sturgeon, Acipenser persicus. Aquacult Int 18: 837-841.

4. Barannikova IA, Dyubin VP, Bayunova LV, Semenkova TB (2002) Steroids in the control of reproductive function of Fish. Neuroscience Behav Physiol 32: 141-148.

5. Schulz RW, De Franca LR, lareyre JJ, Legac F, Chiarini-Garcia H, et al. (2010) Spermatogenesis in Fish. J General and Comparative Endocrinology 165: 390 411.

6. Semenkova TB, Barannikova IA, Kime D E, McAllister BG, Bayunova LV, et al (2002) Sex steroid profiles in female and male Stellate sturgeon during final maturation induced by hormonal treatment. J Appl Ichthyol 18: 375-381.
7. Alavi SMH, Rodina M, Gela D, Linhart O (2012) Sperm biology and control of reproduction in sturgeon:(I) testicular development, sperm maturation and seminal plasma characteristics. Rev Fish Biol Fisheries 22: 695-717.

8. Ueda H, Kambegawa A, Nagahama Y (1985) Involvement of gonadotropin and steroid hormones in spermiation in the Amago salmon, Oncorhynchus rhodurus and goldfish, Carassius auratus. Gen Comp Endocrinol 59:24-30.

9. Miura T, Yamauchi K, Takahashi H, Nagahama $Y$ (1992) The role of hormones in the acquisition of sperm motility in salmonid fish. J Exp Zool 261: 359-363.

10. Vizziano D, Le Gac F, Fostier A (1996) Effect of 17ß-estradiol, testosterone and 11-ketotestosterone on 17,20ß-dihydroxy- 4-pregnen-3-one production in the rainbow trout testis. Gen. Comp. Endocrinol 104:179-188.

11. Wei Q, Li P, Psenicka M, Alavi SMH, Shen L, et al. (2007) Ultrastructure and morphology of sperm in Chinese sturgeon (Acipenser sinensis Gray $1835)$ using scanning and transmission electron microscopy. Theriogenology 67:1269-1278

12. Barannikova IA, Bayunova LV, Semenkova TB (2006) Serum sex steroids and their specific cytosol binding in the pituitary and gonads of Russian sturgeon (Acipenser gueldenstaetdii Brandt) during final maturation. J Appl Ichthyol 22: 331-333.

13. Williot P, Gulyas T, Ceapa C (2002) An analogue of GnRH is effective for induction of ovulation and spermiation in farmed Siberian sturgeon, Acipenser baerii Brandt. Aqua Res 33:735-737.

14. Kime DE (1998) Endocrine disruption in fish. Kluwer Academic Publishers Boston, Dordrecht, London.

15. Bayunova L, Canario AVM, Semenkova T, Dyubin V, Sverdlova O, et al. (2006) Sex steroids and cortisol levels in the blood of stellate sturgeon (Acipenser stellatus Pallas) during final maturation induced by $\mathrm{LH}-\mathrm{RH}$-analogue. J Appl Ichthyol 22: 334-339.

16. Barannikova IA, Bayunova LV, Semenkova TB (2004) Serum levels of testosterone, 11 ketotestosterone and oestradiol-17b in three species of sturgeon during gonadal development and final maturation induced by hormonal treatment final maturation induced by hormonal treatment. J Fish Biol 64: $1330-1338$

17. Yaron Z (1995) Endocrine control of gametogenesis and spawning induction in the carp. Aquaculture 129: 49-73.

18. Bukovskaya O, Lambert JGD, Kime D E (1997) In vitro steroidogenesis by gonads of the Russian sturgeon, Acipenser gueldenstaedti Brandt. Fish Physiology and Biochemistry, Kluwer Academic Publishers 16: 345-353. 